\title{
Studies regarding the influence of the design parameters on the shock behaviour of the parts obtained by 3D Printing technology
}

\author{
Maria Luiza BESLIU-GHERGHESCU*, Monica Daniela IORDACHE, \\ Nicolae Doru STANESCU, Daniel Constantin ANGHEL, Alin Daniel RIZEA \\ University of Pitesti, Pitesti, Romania \\ ${ }^{*}$ Corresponding author e-mail: besliuluiza@yahoo.com \\ Article history \\ Received 20.07.2019 \\ Accepted 15.08.2019 \\ DOI https://doi.org/10.26825/bup.ar.2019.006
}

\begin{abstract}
Over the last decade, more and more parts are manufactured by 3D Printing. This is a printing technology - LPD (Layer Plastic Deposition) being a precise technology for applying the material in order to obtain detailed and accurate prints. This paper presents the bending behavior of the parts obtained by the rapid 3D prototyping technology. 3D printed parts often have anisotropic mechanical properties, more precisely low mechanical properties in the $\mathrm{Z}$ axis direction. To this end, 3D models of test samples with different internal structures, orientations and different dimensions of the geometric shapes that make up these internal structures have been made. The material from which the specimens were made is Z-ULTRAT.
\end{abstract}

Keywords: Charpy, Z-ULTRAT polymeric material, LPD, energy consumed

\section{Introduction}

3D Printing is an emerging manufacturing technology by the addition of molten material, through which complex geometric components can be produced directly from the CAD (Computer Assisted Design) model. The mechanical properties and the lifetime of the parts obtained by 3D Printing are still low compared to those of the parts obtained by conventional technologies, such as: injection molding and thermoforming. To solve this problem, one way is to develop functional materials that have better properties. [1]

A large number of researchers have focused on the optimization of process parameters during the manufacturing phase in order to improve the mechanical properties of the parts manufactured by rapid prototyping technologies. Es Said et al. [2] showed that the raster orientation determines the alignment of the polymer molecules along the direction of deposition during manufacture, and the tensile, bending and impact resistance depends on this orientation. Because the semi-molten filament is extruded through 
the tip of the nozzle and solidified in a room maintained at a certain temperature, a phase change may occur and consequently, a volumetric contraction occurs, which leads to a weak connection between layers and high porosity and therefore, the bearing surface is reduced. Ahn et al. [3] pointed out that process parameters such as air gap and raster orientation significantly influence the breaking resistance of the parts processed by AM. Khan et al. [4] concluded that the thickness of the layer, the angle of deposition and the air gap influence the elastic performance of the ABS prototype.

The aim is to optimize the design parameters to improve the mechanical properties of the parts manufactured by the rapid 3D prototyping technology.

As is well known, impact performance can be one of the most important properties for a component designer and also the most difficult to quantify. The Charpy test consists of breaking a notched specimen in the middle, from a single blow applied with a pendulum. The blow is applied on the opposite side of the notch of the simple recessed specimen. [5]

Charpy test on polymeric material is an impact tests which measure the resistance to failure of a material to a suddenly applied force. The Charpy test measures the impact energy or the energy absorbed prior to fracture. In this paper we measure the impact energy for samples made by $3 \mathrm{D}$ printed polymeric material, called Z-ULTRAT.

We used the method described in ASTM Standard D 6110 to study the impact behavior on samples made by ULTRAT 3D printed by polymeric material. When the striker impacts the samples, the sample absorbed the energy until it yields. At that point, the sample began to undergo plastic deformation. At the moment when the ULTRAT sample couldn't absorb more energy, fracture occurred. $[6,7,8]$

\section{Experimental procedure}

\subsection{Material and specimens}

Z-ULTRAT is a material characterized by high impact resistance, which gives your models a uniform surface texture. This all-purpose material allows us to print 3D elements which require durability, such as end-use parts, which, after continued use, keep their initial shape over the time. With Z-ULTRAT, objects can be produced that have properties comparable to those manufactured by conventional technologies (injection moulding), including functional prototypes, test casings, and mechanical parts. It is an exceptionally durable and time-lasting filament with a diameter of $1.75 \mathrm{~mm}$ and is well-suited for all kinds of high-quality applications: functional prototyping, casings, end-use parts, tools and art. Z-ULTRAT is a thermoplastic material that contains ABS (acrylonitrile-butadiene-styrene), PC (polycarbonate), additives and dyes.

The 3D models were made using the CATIA V5R19 software, and their shape and dimensions are in accordance with ASTM D 6110. (see Table 1)

In the design process of the $3 \mathrm{D}$ models, the shape, the size of the shape and the orientation of the geometric shape of the internal structure for the specimens subjected to bending by shock were varied. Tests were done on polymeric material made from Z-ULTRAT and the dimensions of the specimens are in accordance to ASTM D 6110 or SR EN ISO 179 Charpy plastics test. (see Fig. 1)

The specimens were manufactured using the Zortrax M200 3D printer with different internal structures.

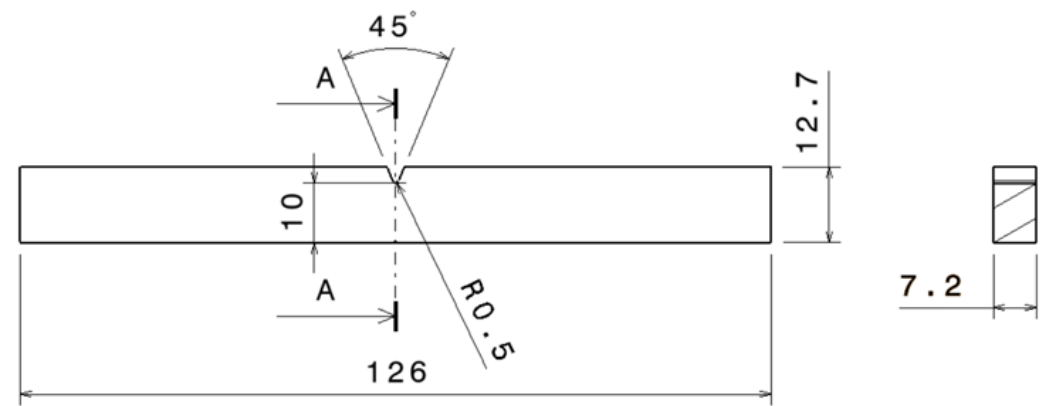

Figure 1. Specimen dimensions 
Table 1 shows the name of the specimens, the type of geometric shapes of the internal structure, the orientation of the geometric shapes and the dimensions of the geometric forms that make up the internal structure and the 3D models.

The specimens denoted A05, A09, A11, A13, A16 have the area of constant geometric shapes, and the specimens denoted A05, A07, A18, A20, A22, A24, A26 have the dimensions of the geometric shapes of the internal structure in constant section, namely: $\mathrm{L}_{\square}=\mathrm{h}_{\Delta}=\mathrm{d}_{\diamond}=\mathrm{D}_{\circ}$.

Table 1. Parameters and 3D models

\begin{tabular}{|c|c|c|c|c|}
\hline No. & $\begin{array}{l}\text { Code } \\
\text { sample }\end{array}$ & $\begin{array}{l}\text { Geometric } \\
\text { shape of the } \\
\text { internal } \\
\text { structure / } \\
\text { Orientation } \\
\text { of the shape }\end{array}$ & $\begin{array}{l}\text { Dimensions } \\
\text { of } \\
\text { geometric } \\
\text { shapes } \\
\text { [mm] }\end{array}$ & 3D Models \\
\hline 1 & $\mathrm{~A} 01$ & infill 100\% & - & \\
\hline 2 & A05 & circle & $\varnothing 2$ & 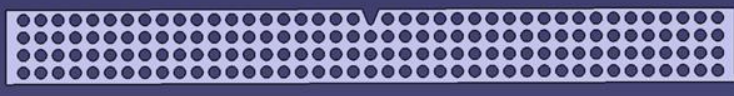 \\
\hline 3 & A07 & square & $\mathrm{L}=2$ & 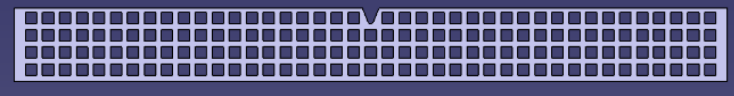 \\
\hline 4 & A09 & square & $\mathrm{L}=1.75$ & 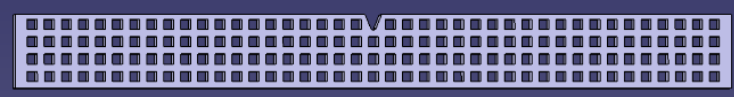 \\
\hline 5 & A11 & rhombus & $\mathrm{d}=2.475$ & 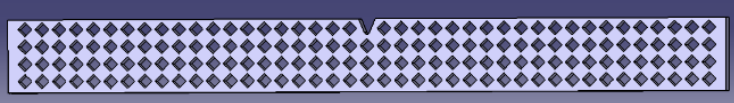 \\
\hline 6 & A13 & $\begin{array}{l}\text { triangle (tip } \\
\text { to notch) }\end{array}$ & $h=2.3$ & 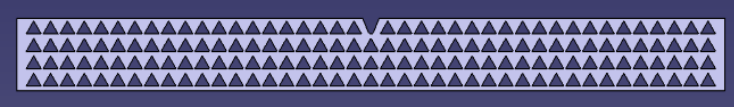 \\
\hline 7 & A16 & $\begin{array}{c}\text { triangle } \mathrm{R} \\
\text { (base to } \\
\text { notch) }\end{array}$ & $h=2.3$ & 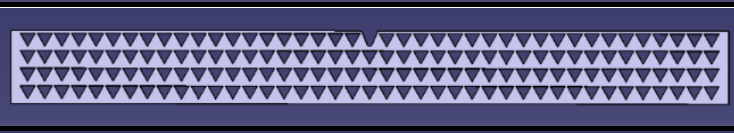 \\
\hline 8 & A18 & $\begin{array}{l}\text { triangle (tip } \\
\text { to notch) }\end{array}$ & $h=2$ & 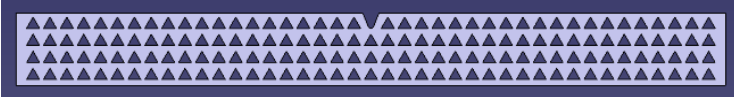 \\
\hline 9 & $\mathrm{~A} 20$ & $\begin{array}{c}\text { triangle } \mathrm{R} \\
\text { (base to } \\
\text { notch) } \\
\end{array}$ & $h=2$ & 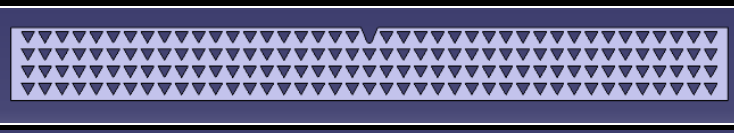 \\
\hline 10 & A22 & $\begin{array}{l}\text { circle }+ \\
\text { triangles } \mathrm{R}\end{array}$ & $\varnothing 2+\mathrm{h}=2$ & 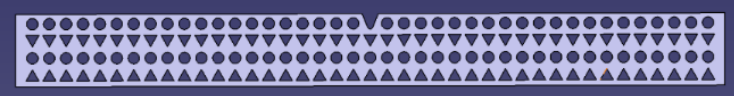 \\
\hline 11 & A24 & rhombus & $d=2$ & 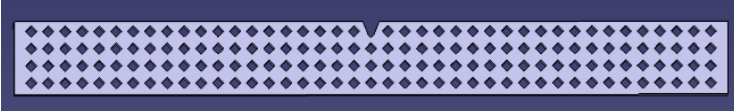 \\
\hline 12 & A26 & $\begin{array}{l}\text { triangle }+ \\
\text { rhombus }\end{array}$ & $\mathrm{h}=\mathrm{d}=2$ & 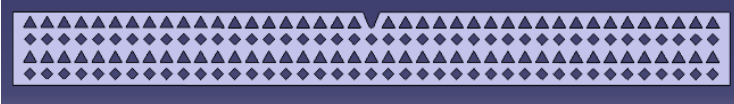 \\
\hline 13 & A27 & circle & $\varnothing 1.5$ & 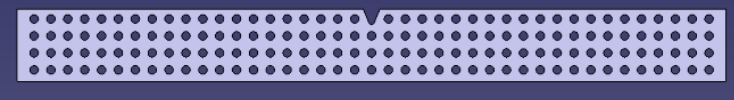 \\
\hline 14 & A29 & circle & $\varnothing 2.5$ & 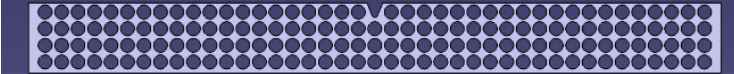 \\
\hline
\end{tabular}




\subsection{Testing equipment}

A simple pendulum impact machine according to ASTM D 6110 or SR EN ISO 179 Charpy plastics testing was used to perform the tests. (see Fig. 2 and 3)

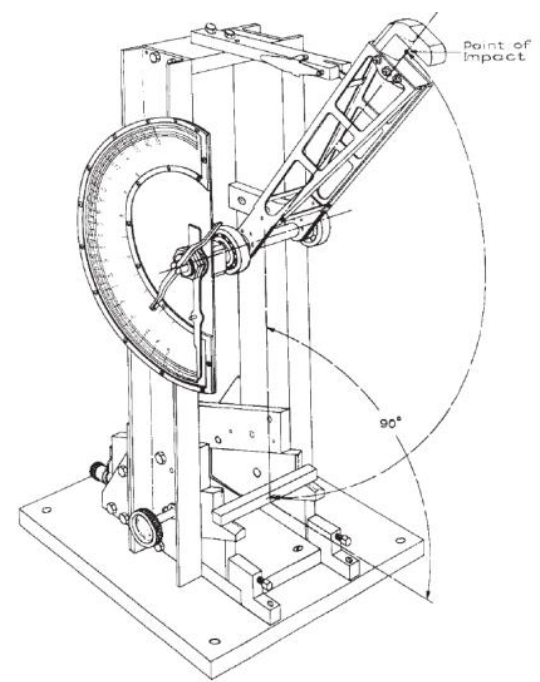

Figure 2. Simple Beam (Charpy-Type) Impact Machine

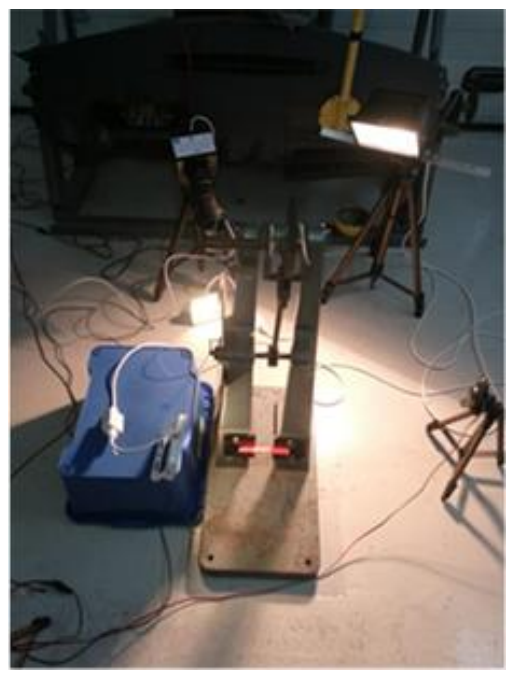

Figure 3. Testing Equipment

For the impact test, the sample is laid horizontally across two end supports. Then, the pendulum is released from the height of $775 \mathrm{~mm}$ to break the sample in the middle and the speed with which the pendulum strikes the specimen is $3.9 \mathrm{~m} / \mathrm{s}$. The sample is notched, and the notch is placed opposite the pendulum impact point.

\section{Results and discussions}

The software applications used in the research carried out are: Catia V5R19 - CAD application, Excel - spreadsheet application, Z-Suite - 3D printing application.

The total energy consumed is calculated in $[\mathrm{J}]$ with the equation:

$$
W_{c}=E_{r} \cdot g
$$

where: $E_{r}$ - the consumed energy recorded after the tests carried out and converted to $[\mathrm{kg} \mathrm{m}]$; $W_{c}$ - consumed energy in $[\mathrm{J}] ; g$ - gravitational acceleration $\left[\mathrm{m} / \mathrm{s}^{2}\right]$.

Calculate the area of the cross-section with the equation (2):

$$
S=l \cdot h
$$

where: $S$ - area of the cross section in $\left[\mathrm{cm}^{2}\right] ; l$ - the width of the cross-section in $[\mathrm{cm}] ; h$ - the height (thickness) of the specimen [cm].

$K_{V C}$ - mechanical shock resistance or resilience in $\left[\mathrm{J} / \mathrm{cm}^{2}\right]$ is determined by the formula (3):

$$
K_{V C}=\frac{W_{c}}{S}
$$

The kinetic energy $(\mathrm{Ec})$ of the pendulum is shown in the table below.

Table 2 presents the experimental data obtained from the tests performed, the values obtained from the calculations in Excel and the cross-sectional dimensions measured by means of a digital caliper. 
Table 2. Experimental data

\begin{tabular}{|c|c|c|c|c|c|c|c|c|c|c|c|c|}
\hline \multirow{2}{*}{$\begin{array}{l}\text { Try. } \\
\text { No. }\end{array}$} & \multirow[b]{2}{*}{ Sample } & \multicolumn{11}{|c|}{ Characteristics } \\
\hline & & $\mathrm{m}[\mathrm{kg}]$ & $\mathrm{H}[\mathrm{m}]$ & $\mathrm{v}[\mathrm{m} / \mathrm{s}]$ & $\mathrm{g}\left[\mathrm{m} / \mathrm{s}^{2}\right]$ & $1[\mathrm{~cm}]$ & $\mathrm{h}[\mathrm{cm}]$ & $\mathrm{S}\left[\mathrm{cm}^{2}\right]$ & Ec [J] & $\begin{array}{c}\mathrm{E}_{\mathrm{r}} \\
{[\mathrm{kgm}]}\end{array}$ & $\begin{array}{l}\mathrm{W}_{\mathrm{c}} \\
{[\mathrm{J}]}\end{array}$ & $\begin{array}{c}\mathrm{K}_{\mathrm{cv}} \\
{\left[\mathrm{J} / \mathrm{cm}^{2}\right]}\end{array}$ \\
\hline 1 & A01 & \multirow{14}{*}{0.774} & \multirow{14}{*}{0.775} & \multirow{14}{*}{3.9} & \multirow{14}{*}{9.81} & \multirow{14}{*}{1} & \multirow{14}{*}{0.72} & \multirow{14}{*}{0.72} & \multirow{14}{*}{5.88627} & 0.1225 & 1.2017 & 1.6691 \\
\hline 2 & A05 & & & & & & & & & 0.085 & 0.8339 & 1.1581 \\
\hline 3 & A07 & & & & & & & & & 0.1275 & 1.2508 & 1.7372 \\
\hline 4 & $\mathrm{~A} 09$ & & & & & & & & & 0.0675 & 0.6622 & 0.9197 \\
\hline 5 & A11 & & & & & & & & & 0.0775 & 0.7603 & 1.0559 \\
\hline 6 & $\mathrm{~A} 13$ & & & & & & & & & 0.1 & 0.981 & 1.3625 \\
\hline 7 & A16 & & & & & & & & & 0.13 & 1.2753 & 1.7713 \\
\hline 8 & A18 & & & & & & & & & 0.105 & 1.0301 & 1.4306 \\
\hline 9 & $\mathrm{~A} 20$ & & & & & & & & & 0.1175 & 1.1527 & 1.6009 \\
\hline 10 & $\mathrm{~A} 22$ & & & & & & & & & 0.0925 & 0.9074 & 1.2603 \\
\hline 11 & A24 & & & & & & & & & 0.1 & 0.981 & 1.3625 \\
\hline 12 & A26 & & & & & & & & & 0.09 & 0.8829 & 1.2263 \\
\hline 13 & A27 & & & & & & & & & 0.055 & 0.5396 & 0.7494 \\
\hline 14 & A29 & & & & & & & & & 0.084 & 0.8216 & 1.1411 \\
\hline
\end{tabular}

Figure 4 shows the difference between the kinetic energy and the energy consumed for each sample that was tested.

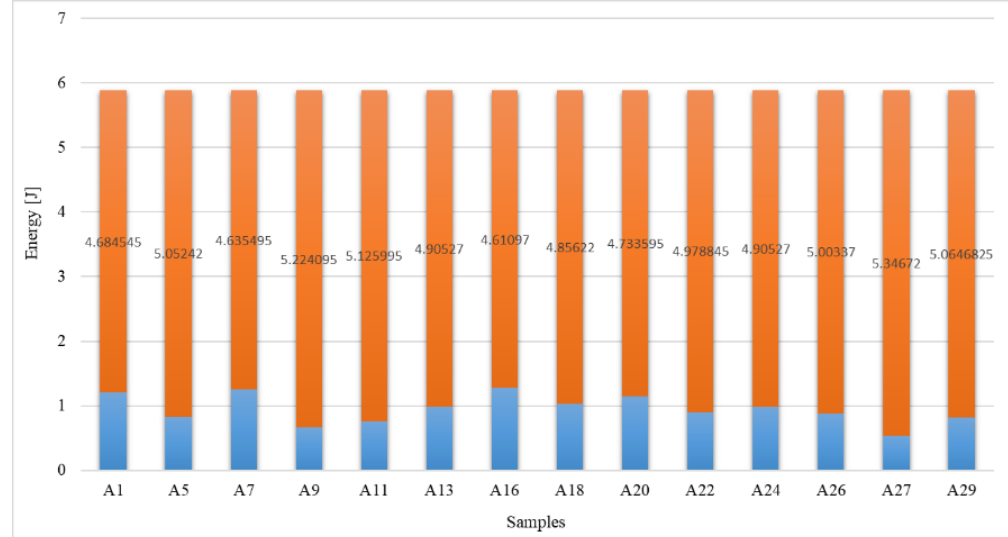

Figure 4. Difference between kinetic energy and energy consumed

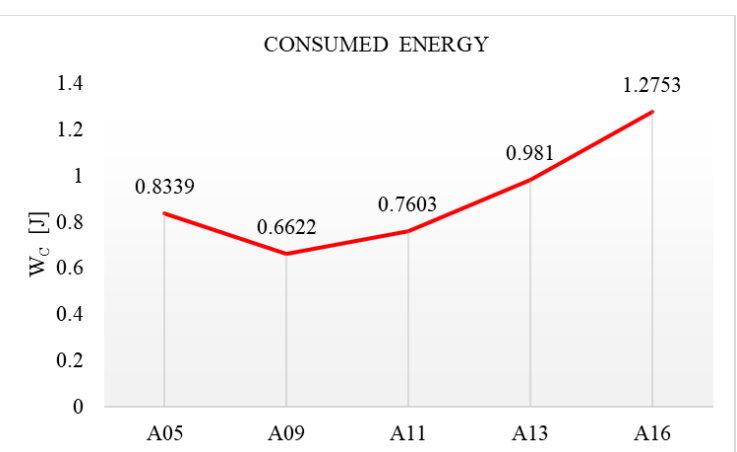

Figure 5. The variation of the energy consumed for the samples $($ Area $=$ ct. $)$

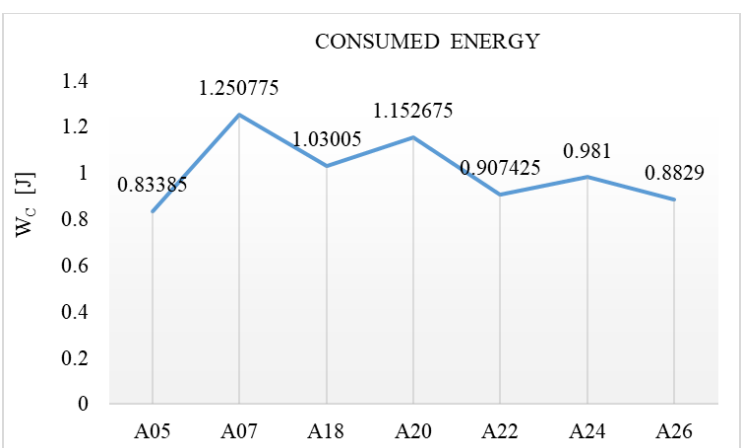

Figure 6. The variation of the energy consumed for the samples with $\mathrm{L}_{\square}=\mathrm{h}_{\Delta}=\mathrm{d}_{\diamond}=\mathrm{D}_{\circ}=2[\mathrm{~mm}]$

In the case of specimens with a geometric circle shape A05, A27, A29 for smaller diameters the rupture is performed between the rows and a smaller amount of energy is consumed (the crack propagates through the areas with lower density). Circles and more energy is consumed to break the hardened areas (between the rows of circles there are no denser areas). 
Regarding the influence of the geometric shape, samples with the same area shapes were analyzed (A05, A09, A11, A13, A16). The energy consumed differs from one form to another, but it was found that in the case of the specimen having the geometric form of the internal structure of a triangle type, the maximum quantity is absorbed. (Figure 5)

Regarding the influence of the geometric shape, we analyzed the samples written A05, A07, A18, A20, A22, A24, A26 which have the dimensions of the geometric shapes of the internal structure in constant section, namely: $\mathrm{L} \square=\mathrm{h} \Delta=\mathrm{d} \diamond=\mathrm{D} \circ$. It is found that the energy consumed is maximum in the case of the test with the internal structure of square type. (Figure 6)

In the specimens with the internal geometric structure of the square type the energy absorbed is minimal, because the difference between the geometric structure of the square type and that of the circle type is that in the square type the road where the rupture occurred is perpendicular (the road is shorter), whereas in the specimens with a geometric structure of a circle type the road on which the rupture took place is longer because it tends to follow the circumference of the circle, more precisely the contour lines. The contour lines are tracked because the material in those areas is denser.

Figure 7 shows the trajectory of the crack for the specimens with internal structure of square type with side $1.75[\mathrm{~mm}]$ and circle type with diameter of $2[\mathrm{~mm}]$.

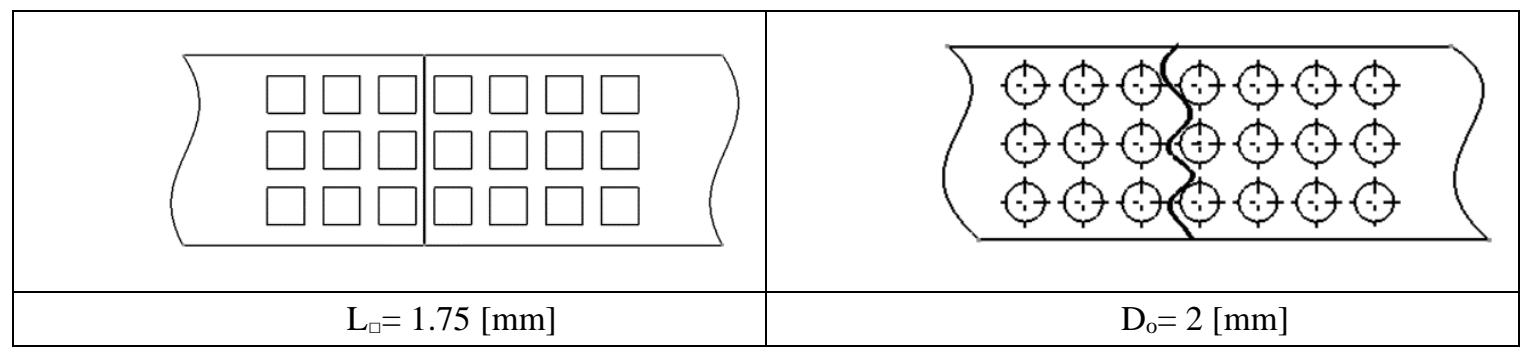

Figure 7. Fracture line

The circle does not allow the crack to enter the structure, it forces the path of the crack to bypass the structure, therefore we consider that the path of the crack can be steered.

\section{Conclusion}

The behavior of impact for the parts obtained by 3D Printing is important for the designers. This work aimed at analyzing the influence of design parameters on the behavior of the products obtained by 3D Printing from the Z-ULTRAT material. It has been noticed that better shock behaviors have been obtained in the case of larger hollow parts due to the fact that the porous materials behave better than the dense ones.

In these materials, tenacity or impact resistance is defined by their ability to absorb energy, usually measured by the amount of energy / unit volume required to break the test specimen.

The Charpy test is most commonly used to evaluate the relative hardness or impact hardness of the materials and, as such, is often used in quality control applications where it is a relatively easy, fast and economical test. It is used more as a comparative test than a definitive test.

In conclusion, design parameters may have a greater or lesser influence on the shock behavior of parts obtained by 3D Printing technology.

After subjecting the samples obtained by rapid prototyping to the Charpy test, it was observed that the geometric shape and the size of the geometric shape of the internal structure of the parts influence the shock behavior. Specimens A7, A16, A20 recorded the maximum amount of energy consumed, and specimens A09, A11, A27 recorded the minimum amount of energy consumed.

\section{References}

[1] Mohamed, O., Masood, S., \& Bhowmik, J. (2017). Characterization and dynamic mechanical analysis of PC-ABS material processed by fused deposition modelling: An investigation through I-optimal response surface methodology. Measurement: Journal of the International Measurement Confederation, 107, 128141. 
[2] Es-Said, O. S., Foyos, J., Noorani, R., Mendelson, M., Marloth, R., \& Pregger, B. A. (2000). Effect of layer orientation on mechanical properties of rapid prototyped samples. Materials and Manufacturing Processes, 15(1), 107-122.

[3] Ahn SH, Montero M, Odell D, Roundy S, Wright PK. Anisotropic materialmproperties of fused deposition modelling ABS. Rapid Prototyp J 2002;8(4):248-57.

[4] Khan ZA, Lee BH, Abdullah J. Optimization of rapid prototyping parameters for production of flexible ABS object. J Mater Process Technol 2005; 169:54-61.

[5] http://www.sim.utcluj.ro/stm/download/tehnologie/LucrariLab_TM.pdf

[6] Anghel, D. C., Rizea, A. D., Iordache, D. M., \& Beşliu-Gherghescu, M. L. (2019, October). Studies on the influence of design parameters on the behaviour at shock of 3D-printed components fabricated by fused deposition modelling. In IOP Conference Series: Materials Science and Engineering (Vol. 564, No. 1, p. 012014). IOP Publishing.

[7] Tabacu, S., \& Ducu, C. (2018). Experimental testing and numerical analysis of FDM multi-cell inserts and hybrid structures. Thin-Walled Structures, 129, 197-212.

[8] Caminero, M. A., Chacón, J. M., García-Moreno, I., \& Rodríguez, G. P. (2018). Impact damage resistance of 3D printed continuous fibre reinforced thermoplastic composites using fused deposition modelling. Composites Part B: Engineering, 148, 93-103.

\section{Acknowledgments}

This work was supported by a grant of the Romanian Ministry of Research and Innovation, CCCDI-UEFISCDI, project number PN-III-P1-1.2-PCCDI-2017-0224/77 PCDI/2018 within PNCDI III. 